\title{
The fumigant and repellent activity of aliphatic lactones against Pediculus humanus capitis (Anoplura: Pediculidae)
}

\author{
Ariel Ceferino Toloza, Julio Zygadlo*, Gastón Mougabure-Cueto, Eduardo Zerba/**, \\ Silvina Faillaci*, María Inés Picollo/ ${ }^{+}$
}

\begin{abstract}
Centro de Investigaciones de Plagas e Insecticidas, J. B. de La Salle 4397 (B1603ALO), Provincia de Buenos Aires, Argentina
*Cátedra de Química Orgánica y Productos Naturales, Universidad de Córdoba, Córdoba, Argentina **Universidad Nacional

General San Martín, Buenos Aires, Argentina
\end{abstract}

New alternative insecticides are necessary for the chemical control of head lice. In this study the fumigant knockdown time $50 \%\left(K T_{50}\right)$ and repellency index $(R I)$ of three aliphatic lactones was compared with two essential oils and DDVP, against permethrin-resistance Pediculus humanus capitis from Argentina. In the fumigant assay, none of the lactones were effective compared to the highest activity of eucalyptus $\left(K T_{50} 15.53 \mathrm{~m}\right)$. In the repellency test, the three lactones were equally or more effective (RI ranging from 60.50 to 76.68 ) than the positive control (piperonal). These lactones are promising as head lice repellents.

Key words: aliphatic lactones - permethrin-resistance - head lice

Head lice infestation with Pediculus humanus capitis De Geer, is a worldwide health problem affecting most of the primary school-aged children in developed and developing countries (Burgess 2004). The repeated application of insecticides has resulted in the development of resistance to these products (Picollo et al. 1998, Vassena et al. 2003, Burgess 2004). Recent concerns with human health and environmental safety have prompted a revival of interest in plant-derived insecticides. Aliphatic lactones are widely found in many different fruits playing important roles in flavors (Zarbin et al. 2004). In addition, essential oils (EO) of plant tissues have been widely reported as insecticides (Isman 1999). The purpose of the present work was to evaluate the fumigant and repellent activity of three aliphatic lactones against permethrin-resistant head lice from Argentina. Two EO (eucalyptus and lavender) and two insecticides (DDVP and piperonal) were used as positive controls.

\section{MATERIALS AND METHODS}

Head lice were collected using an anti-louse comb from 60 infested children of two elementary schools from Buenos Aires. Permethrin-resistance had previously been reported from the same schools as the lice were collected (Vassena et al. 2003). The $\delta$-lactone (delta-hexalactone-5methylpentanolide), $\gamma$-nonalactone (4-pentylbutanolide) and $\delta$-dodecalactone (5-heptylpentanolide), were from Palma Chemicals (Argentina), the eucalyptus and lavender from Fritzsche Saica (Argentina). The purity of each compound was more than $99 \%$ as measured by HPLC analysis. The piperonal (1,3-benzodioxol-5-carboxaldehyde) (99\%) was from Aldrich (US) and the DDVP (2,2-dichlorovinyl dimethyl phosphate) (97.8\%) from

${ }^{+}$Corresponding author: mpicollo@ citefa.gov.ar Received 10 August 2005 Accepted 4 January 2006
Chemotecnica (Argentina). Certified acetone was used as control treatment in the repellent experiments.

The direct vapor contact was evaluated in an enclosed chamber consisting of a $9 \mathrm{~cm}$ Petri dish where $60 \mu \mathrm{l}$ of the tested substance was placed within. A $5.5 \mathrm{~cm}$ Petri dish with a Whatman No.1 filter paper and 15 adult head lice were placed within the chamber (Figure). The control test was performed using the chamber without any test substance included. Knockdown was recorded every $5 \mathrm{~min}$ for $1 \mathrm{~h}$.

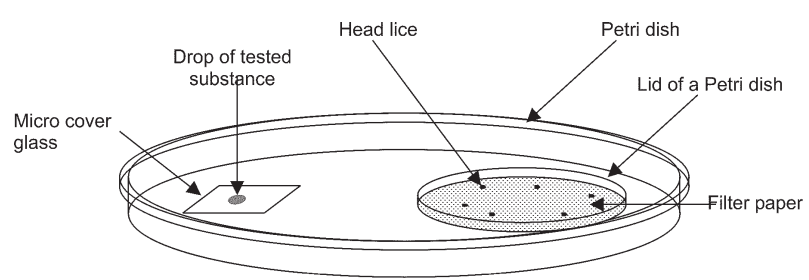

Schematic view of vapour exposure enclosed test chamber

Repellency was evaluated in a test arena consisting of a filter paper (Whatman No.1, $11 \mathrm{~cm}$ diameter) divided into an inner zone (a) and outer zone (b), both with equal areas. Treatment consisted of $0.5 \mathrm{ml}$ of the tested solutions in acetone $(50 \mathrm{mg} / \mathrm{ml})$ applied on zone b resulting in a final concentration of $0.7 \mathrm{mg} / \mathrm{cm}^{2}$ on the paper. Control consisted of both zones treated with acetone. All treated filter papers were allowed to dry for $10 \mathrm{~min}$ before use. Batches of 15 adults were placed in the zone a, the number of lice found on both zones was recorded every $5 \mathrm{~min}$ for $1 \mathrm{~h}$. The DDVP and piperonal were employed as positive controls for fumigant and repellency activity (Burgess 2004). The EO of eucalyptus and lavender were used to compare either fumigant or repellent activity of the lactones. All the insects were kept at $28 \pm 1{ }^{\circ} \mathrm{C} ; 60 \pm 5 \% \mathrm{RH}$.

All knockdown data were subject to probit analysis to estimate knockdown time $50 \%\left(\mathrm{KT}_{50}\right)$ by the POLO PC 
TABLE

Fumigant and repellent activity of aliphatic lactones, essential oils, DDVP, and piperonal against Pediculus humanus capitis

\begin{tabular}{|c|c|c|c|c|}
\hline \multirow[b]{2}{*}{ Components ${ }^{a}$} & \multicolumn{3}{|c|}{ Fumigant activity } & \multirow{2}{*}{$\frac{\text { Repellent activity }}{\mathrm{RI} \pm \mathrm{SE}}$} \\
\hline & $\mathrm{KT}_{50}(\min , 95 \% \mathrm{CL})$ & Slope \pm SE & $\chi^{2}$ & \\
\hline$\delta$-lactone & $>60$ & & & $68.46 \pm 1 \mathrm{ef}$ \\
\hline$\gamma$-nonalactone & $>60$ & & & $60.50 \pm 3 \mathrm{ef}$ \\
\hline$\dot{\delta}$-dodecalactone & $>60$ & & & $76.68 \pm 7 f$ \\
\hline Piperonal & - & & & $72.26 \pm 11 f$ \\
\hline Eucalyptus & $15.53(11.74-18.53)$ & $5.34 \pm 1.22$ & 1.88 & $50.22 \pm 15 \mathrm{de}$ \\
\hline Lavender & $44.6(39.67-50.82)$ & $8.13 \pm 1.93$ & 2.85 & $31.72 \pm 9 d$ \\
\hline DDVP & $40.15(34.63-48.86)$ & $3.93 \pm 0.68$ & 7.27 & - \\
\hline
\end{tabular}

$a$ : for each essential oil and for each treatment, the number of head lice was 45; CL: confidence limit; RI \pm SE: repellency index \pm standard error. Means in the repellent activity column followed by different letters are significantly different after performing the Duncan test $(\mathrm{P}<0.05)$.

program. The repellency index (RI) was calculated according to $\mathrm{RI}=[(\mathrm{Nc}-\mathrm{Nt}) / \mathrm{Nc}]^{*} 100$, where $\mathrm{Nc}$ is the percentage in zone b for the control, and $\mathrm{Nt}$ is the percentage in the zone $b$ of the treatment. The RI means were analyzed by ANOVA. The means were separated using the Duncan test.

\section{RESULTS}

The fumigant and repellency activity of the tested substances against permethrin-resistance head lice are shown in the Table. The aliphatic lactones showed no fumigant activity $\left(\mathrm{KT}_{50}>60 \mathrm{~m}\right)$, compared to eucalyptus $\left(\mathrm{KT}_{50} 15.53 \mathrm{~m}\right)$ that was 2.58 and 2.87 -fold more effective than Lavender and DDVP. The repellency results showed the highest activity for the $\delta$-dodecalactone (RI 76.68), which was significantly different from the more limited repellent effect of the essential oils. Lavender was significantly different from the aliphatic lactones (ANOVA $\mathrm{p}<$ 0.001 ) but showed no difference from eucalyptus.

\section{DISCUSSION}

Previous authors have mentioned the fumigant and repellent activity of EO against human lice (Burgess 2004), but no reports concerning to the pediculicida activity of aliphatic lactones were done. Our results demonstrated that these lactones were as effective as the well known repellent piperonal, and showed higher repellent indexes (RI 68.46, 60.50, and 76.68) than those previously reported for EO components (less than 50\%) against $P$. h. humanus (Mumcuoglu et al 1996).
These results also suggest that aliphatic lactones could be incorporated in formulations suitable for application to hair capable to produce an adequate slow release, and act as a repellent formulation applied directly to the hair of the persons protecting them from head lice infestation.

\section{REFERENCES}

Burgess IF 2004. Human lice and their control. Annu Rev Entomol 49: 457- 481.

Isman M 1999. Pesticides based on plant essential oils. Pestic Outlook 10: 68-72.

Mumcuoglu K, Galun R, Bach U, Miller J, Magdassi S 1996. Repellency of essential oils and their components to the human body louse, Pediculus humanus humanus. Entomol Exp Appl 78: 309-314.

Picollo MI, Vassena C, Casadio A, Massimo J, Zerba E 1998. Laboratory studies of susceptibility and resistance to insecticides in Pediculus capitis (Anoplura; Pediculidae). J Med Entomol 35: 814-817.

Vassena C, Mougabure Cueto G, González Audino P, Alzogaray R, Zerba E, Picollo MI 2003. Prevalence and levels of permethrin resistance in Pediculus humanus capitis De Geer (Anoplura: Pediculidae) from Buenos Aires, Argentina. J Med Entomol 40: 447-450.

Zarbin P, Oliveira A, Simonelli F, Villar J, Delay O 2004. An easy and versatile approach to the synthesis of chiral pheromone lactones via 4, 4-dimetyl-2-oxazoline derivatives. Tetrahedron Lett 45: 7399-7400. 